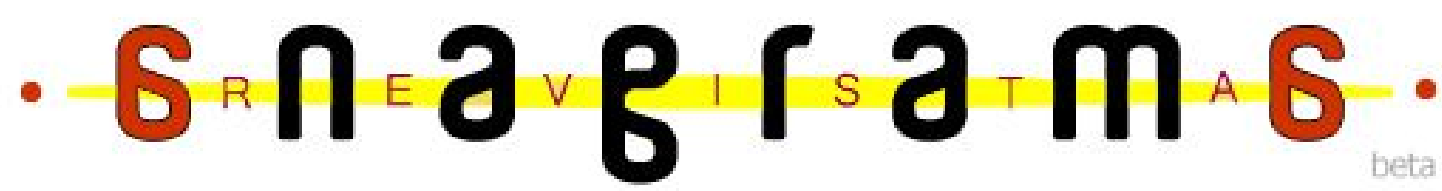

\section{Memórias da ditadura: a experiência de uma rádio em cidade}

\section{fronteiriç̧a}

Wesley Pereira Grijót

Camila Cananea ${ }^{2}$

Filipe Fernandes ${ }^{3}$

Uera Santos ${ }^{4}$

Thiara Tezza

\section{Resumo}

O artigo aborda a experiência da Rádio Cultura AM, situada na cidade de São Borja, fronteira oeste do Rio Grande do Sul, durante o período ditatorial no Brasil. Dessa forma, tem-se como objetivo evidenciar a memória radiofônica local a partir da experiência de um profissional que vivenciou aquele período. Aproxima-se a memória radiofônica do contexto são-borjense à preservação da memória coletiva. Nos procedimentos metodológicos, a pesquisa é abordagem qualitativa, utilizando a pesquisa bibliográfica e documental para obtenção de dados, além disso, utiliza-se o método da História oral e a técnica da entrevista semiestruturada para coleta de informações com o radialista. Observase que mesmo com a vigília ditatorial, a censura não foi o suficiente para inibir por completo a programação da rádio. O período militar obrigou a rádio a investir em novas abordagens de trabalho de modo a preservar a audiência e não atrair a censura: a solução foi a cobertura futebolística.

Palauras-chaue: Rádio; História Oral; Memória; Ditadura Militar; São Borja-RS.

\footnotetext{
1 Doutor em Comunicação e Informação pela Universidade Federal do Rio Grande do Sul. Professor da Universidade Federal do Pampa, Campus São Borja-RS. Email: wgrijo@yahoo.com.br.

2 Acadêmica do curso de Licenciatura em Ciências Humanas pela Universidade Federal do Pampa, campus São Borja-RS. Email. Camilacananeamartins@gmail.com.

3 Acadêmico do curso de Licenciatura em Ciências Humanas pela Universidade Federal do Pampa, campus São Borja-RS. Email. filipegfernandes@hotmail.com

4 Acadêmica do curso de Ciência Política, pela Universidade Federal do Pampa, campus São Borja - RS.

5 Bacharel em Ciência Política, pela Universidade Federal do Pampa, campus São Borja - RS. Email: thiaratezza@hotmail.com.
} 


\section{Introdução}

O ano de 2014 marcou o aniversário de um dos períodos mais vergonhosos e tristes da história recente do Brasil: a Ditadura militar. No Brasil, o regime ditatorial-militar durou 25 anos, de 1964 a 1989, teve seis governos - incluindo um governo civil - e sua história pode ser dividida em cinco grandes fases. (FERNANDES, 1981; GASPARI, 2002a; 2002b; 2003; 2004)

Tomando como recorte de pesquisa o período ditatorial, este artigo aborda a experiência de uma rádio situada na cidade de São Borja, fronteira oeste do Rio Grande do Sul. Dessa forma, tem-se como objetivo evidenciar a memória radiofônica local a partir da experiência de um profissional que vivenciou aquele período ${ }^{6}$.

Dessa forma, para coletar as informações relativas à memória radiofônica na cidade de São Borja, este estudo parte do viés metodológico qualitativo (FLICK, 2004), baseado na pesquisa documental e bibliográfica. Para a coleta de informações que não estão contempladas nas fontes oficiais, utilizamos o método da História Oral e a técnica da entrevista semiestruturada para essa finalidade, tendo como informante um experiente radialista da cidade. Nessa questão, temos um pensamento convergente com Cruikshank (2000), quando afirma que os estudos sobre a tradição oral estão mais propensos focalizála não só na formação das narrativas como também o posicionamento dessas formas narrativas nas hierarquias de outras narrativas. Na entrevista, seguimos as indicações de Alberti (2005) e Harres (2008) para a utilização da História Oral.

Neste estudo, aproximamos a memória radiofônica do contexto são-borjense à preservação da memória coletiva, considerando que esta é sempre uma construção feita no presente a partir de vivências ocorridas no passado. Para Halbwachs (1990), a memória está atrelada às relações sociais coletivas. Nesse sentido, a lembrança não se constrói sem memória coletiva. Assim, este autor nos ajuda a pensar que o indivíduo que lembra é sempre um indivíduo inserido e habitado por grupos de referência, a memória é sempre construída em grupo, mas é também, um trabalho do sujeito.

${ }^{6}$ Pesquisa foi realizada na disciplina Política e Mídia, ministrada na Universidade Federal do Pampa (Unipampa), Campus São Borja. Contribuíram ainda para a pesquisa os acadêmicos do curso de Ciências Humanas e Ciências Políticas: Alessandra Almeida, Assis Brasil, Gabriela Brasil, Guilherme Minozzo, Cláudia da Silva, Núbia Velasque. 


\section{Rádio, história e política}

Conforme apontam Prado (2012) e Moreira (1991), com o surgimento da primeira rádio do Brasil na década de 1920, ocorreram mudanças significativas nas relações sociais e políticas na comunicação de massa no país. Para Haussen (2001), a influência da rádio na política brasileira e inegável. Um dos pontos chave para entender essa questão começa com o decreto $n^{\circ}$ 20.047, de 1931. Para então presidente brasileiro, o são-borjense Getúlio Vargas, o veículo rádio era de extrema importância para o desenvolvimento de seu mandato, pois servia para divulgação das realizações do governo ao mesmo tempo em que visibilidade ao chefe do Executivo nacional.

Assim, iniciou-se um novo modo de fazer política, além de ser um novo campo econômico. As trocas de informações, o processo de mediação (produção e reprodução) acabaram virando ideologia. E, muitas vezes, essas ideologias ajudavam a sustentar relações de poder, como ressalta Thompson (1995, p.16): “ideologia, falando de uma maneira mais ampla, é sentido a serviço do poder".

Dessa forma, muito antes da implantação da Ditadura militar no Brasil, Prado (2012), Haussen (2001) e Moreira (1991), afirmam que esse meio de comunicação sempre foi muito bem utilizado para fins políticos. Esse processo iniciou na Era Vargas, que moldou e soube utilizar o rádio a seu favor, nascendo assim uma nova maneira de fazer política.

Historicamente, a década de 1930, é marcada pelo aumento da produção de aparelhos de rádio, embora os componentes continuassem sendo importados, assim como pelo gradual crescimento da presença do aparelho nos lares das famílias brasileiras. Naquele mesmo ano, Getúlio Vargas autoriza a veiculação de propaganda pelo rádio, o que possibilitaria uma relação das emissoras com o mercado para a obtenção de lucro e assim terem condições de fazer a manutenção das emissoras. Entre 1932 e 1937 foram instaladas no Brasil 42 novas estações, que, somadas às existentes, totalizaram 63.

Os estudos sobre história do rádio revelam que esse meio de comunicação foi um instrumento importante na divulgação da política do Estado Novo. Nesse contexto político, Getúlio Vargas soube como utilizá-lo em suas ações políticas disseminando sua figura nos lares das famílias brasileiras. A partir da década de 1940, surge o programa que melhor materializaria a relação entre o rádio e a política no Brasil, a Voz do Brasil. Na prática, o programa servia para o culto de veneração à pátria, assim como a reabilitação da dignidade 
do trabalho e do trabalhador e todas as emissoras de rádio existentes no país eram obrigadas a fazer a sua transmissão.

Esse interesse de Getúlio Vargas pelo rádio já era evidente antes do golpe que implantou o Estado Novo. Já em 1937, o presidente em seu famoso discurso de $1^{\circ}$ de maio acenou que o governo estava ultimando esforços para aumentar o número de estações radiofônicas e anunciou o propósito de instalar em todo o interior do país receptores providos de alto-falantes, em espaços públicos. Em 1944, havia 106 estações em funcionamento; em 1945, 111. Durante o Estado Novo, o número de aparelhos receptores registrados subiu de 357.921, em 1939, para 659.762 em 1942.

Outro momento importante na relação do rádio e da política no Brasil ocorreu no Rio Grande do Sul, em 1961, envolvendo dois políticos oriundos da cidade de São BorjaRS: João Goulart e Leonel Brizola. Segundo Machado (2011), a chamada "Campanha da Legalidade", foi um dos maiores movimentos cívicos da história do país e que aglutinou uma parcela da população sul-rio-grandense em defesa da posse do então vice-presidente João Goulart, o Jango, após da renúncia do paulista Jânio Quadros.

Com a iminência de um golpe orquestrado por ministros militares, o governador gaúcho naquele período, Leonel Brizola, entrou em cena para cobrar a posse do cunhado e aliado político. Entretanto, para efetivar sua posição o governador tinha poucas alternativas além de um limitador contingente militar. Entretanto, Brizola conseguiu mobilizar a população gaúcha e a Brigada militar local em defesa da legalidade e da posse de Jango como presidente. Ainda conforme Machado (2011), além de ter distribuído armas à população e conseguido o apoio da Brigada Militar, o governador Brizola requisitou a Rádio Guaíba ${ }^{7}$, visto que todas as rádios que defendiam a legalidade estavam sendo colocadas fora do ar. Assim, o político utilizando seu poder de comunicação e a grande difusão do rádio entre a população, conseguiu conclamar os gaúchos em defesa da posse do presidente gaúcho. Por conta do que ouviam na rádio, as pessoas se alistavam voluntariamente para atuar nas mais variadas funções, e o Palácio Piratini ${ }^{8}$ se transformou em um núcleo defensor da ordem e dos valores democráticos.

Por conta da repercussão do que ocorreu na rádio Guaíba, outras emissoras se juntaram à defesa da legalidade da posse de Jango, formando a Rede da Legalidade.

\footnotetext{
${ }^{7}$ Emissora de rádio gaúcha inaugurada no dia 30 de abril de 1957, sediada em Porto Alegre. Opera em AM na frequência $720 \mathrm{kHz}$ e em FM, na frequência $101.3 \mathrm{MHz}$.

${ }^{8}$ Sede do governo gaúcho.
} 
Posteriormente, os "legalistas" obtiveram o apoio do governador do Estado de Goiás, Mauro Borges, que passou a liderar a defesa da ordem naquele estado. Assim, João Goulart recuperou os poderes políticos em 1963, mas posteriormente foi derrubado por um golpe militar de 1964.

Com o governo ditatorial dos militares, o veículo rádio continuou como estratégico para a difusão das políticas governamentais. Com a bandeira de manter a "segurança nacional", os militares implementaram uma política modernizadora nas telecomunicações no Brasil: em 1965 foi criada a Embratel $^{9}$ e assim o país associou-se a Intelsat ${ }^{10}$; em 1967 foi criado o Ministério das Comunicações; em 1968 surgiram as primeiras emissoras de frequência modulada $(\mathrm{FM})$; no mesmo ano foi criada a $\mathrm{AERP}^{11}$ que reforçava a necessidade de propagar ideais ufanistas e nacionalistas; em 1969, o país se integra ao sistema mundial de comunicação por satélite e é criada a Embrafilme (empresa estatal que financiava a produção cinematográfica brasileira).

Os estudos sobre história do rádio no Brasil de Prado (2012), Haussen (2001), Moreira (1991), quando se referem ao cenário da Ditadura militar indicam que concomitante a esta política de incentivo esteve a censura dos meios de comunicação que se instaurou no país, principalmente depois do AI-5 (Ato Institucional número 5), em 1968. O AI-5 possibilitou o fechamento do Congresso Nacional e decretou prisões, cassações e a instituição da censura nos meios de comunicação. Assim, as emissoras de rádio não podiam divulgar notícias sobre presos políticos, greves e crises do governo. Foi o ponto decisivo para a centralização militar do poder e o estabelecimento da censura efetiva.

A partir da década de 1970, o setor das comunicações no Brasil, incluindo as emissoras de rádio, foi marcado por investimentos significativos na área; pela consolidação de grandes grupos como a Rede Globo e a Editora Abril; pelo crescimento da publicidade; e pela formação de conglomerados jornalísticos. Não podemos deixar de mencionar que tais processos que já vinham ocorrendo desde meados dos anos de 1960, mas que se consolidam na década posterior. É dentro desse cenário ditatorial que abordamos a experiência de uma rádio situada em São Borja, no Rio Grande do Sul, na fronteira do Brasil com a Argentina e cidade Natal de dois presidentes da República.

\footnotetext{
${ }^{9}$ Empresa Brasileira de telecomunicações.

${ }^{10}$ Sistema Internacional de Satélites.

${ }^{11}$ Assessoria Especial de Relações Públicas.
} 


\section{São Borja: a relaç̧ão da rádio local com a Ditadura militar}

Para discutirmos a relação entre rádio e política, enfocamos nosso estudo em uma emissora de rádio situada na cidade de São Borja-RS, local de onde grandes nomes da política nacional emergiram como Getúlio Vargas, João Goulart e Leonel Brizola.

Localizada no extremo sul do país (Figura 1), São Borja é uma cidade politicamente histórica e vestígios de seu passado perpetuam até os dias de hoje, bem como arquitetura de diversos povos que passaram por esse território, deixando um pouco de si, entre eles os principais são os indígenas guaranis, portugueses e espanhóis. Assim, a cidade destaca-se pela riqueza histórica e pelo reconhecimento de sua importância sociocultural para o Rio Grande do Sul e para o Brasil.

Figura 1: Localização da cidade de São Borja no estado do Rio Grande do Sul.

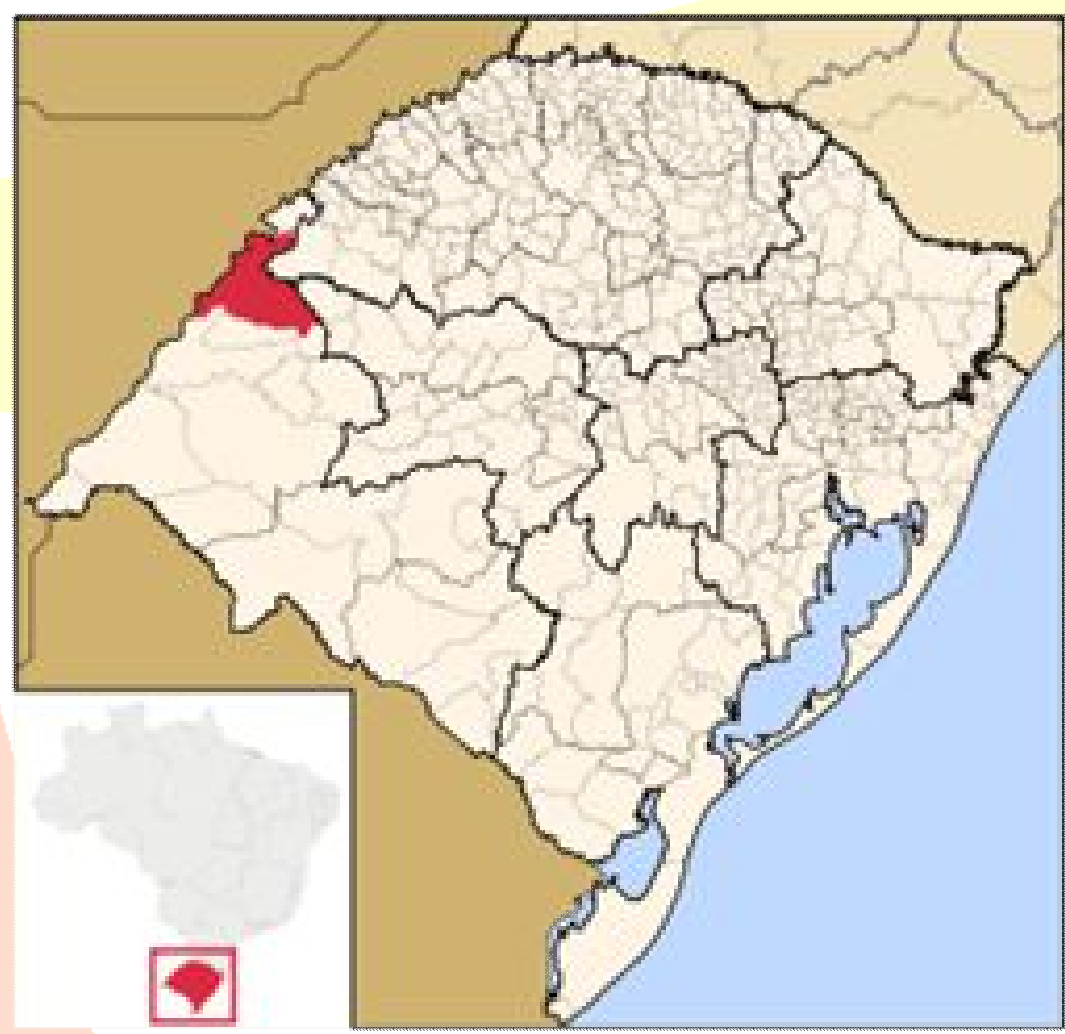

Fonte: Wikipédia.

A trajetória política e social que o município teve é uma fonte viva e diversificada de acontecimentos com relevância histórica. Desde os primeiros povoados missioneiros, a condição de vila, a elevação a município, as invasões paraguaias e a economia baseada em 
pecuária e na agricultura: da sua formação guarani-jesuítica até o local de nascimento de dois dos principais presidentes da República (Getúlio Vargas e João Goulart). (COLVERO; MARTINEZ; MIRANDA, 2014)

A maior parte da população são-borjense é arraigada de crenças religiosas, certamente pelo fato de ter sido fundada por padres jesuítas, sendo ela a primeira aldeia da segunda fase das reduções dos chamados "Sete Povos das Missões". Também conhecida nacionalmente como "Terra dos Presidentes" é parte importante na história política do Brasil.

O município de São Borja detém, no aspecto de sua formação política e patrimonial, boa parte da história nacional. Ao ostentar o título de "Cidade Histórica", tem como cidadãos ilustres os ex-presidentes da República, Getúlio Vargas e João Goulart, e o ex-governador do Rio Grande do Sul e do Rio de Janeiro, Leonel Brizola. Por suposto, não são poucas as pessoas comuns que trazem, através de suas lembranças, dados sobre ambas as figuras. E, é neste sentido, que a história oral, como parte integrante da dimensão de pesquisa, pode oferecer versões que confrontam ou confirmam os dados oficiais. No contexto da cidade, podemos encontrar pessoas ainda vivas que conviveram nas décadas de 1950 e 1960 com Vargas e Jango, testemunharam fatos e vivenciaram acontecimentos desse período e ainda contribuem para enriquecer a história.

Dentre toda a rica história da cidade desde a sua fundação até os dias de hoje, cabenos nesta pesquisa apontar a história de uma emissora de rádio em São Borja e a delicada relação com a Ditadura Militar. Atualmente, na cidade podem ser encontradas as rádios Cultura AM, Fronteira FM, Butuí FM e Navegantes FM que participam da rotina informativa dos são-borjenses. A primeira experiência da comunidade são-borjense com a radiodifusão ocorreu na década de 1940 com a fundação da Rádio Fronteira do Sul, que funcionou sem autorização oficial até o ano de 1945.

Para a pesquisa, enfocamos a história da Rádio Cultura AM, fundada em 26 de fevereiro de 1977 (Foto 1), no momento de Ditadura Militar no país e num período em que o governo tinha como política a difusão das telecomunicações nos mais diversos locais do país, inclusive as regiões de fronteira como é o caso de São Borja. 
Foto 1: Fachada antigo da Rádio Cultura

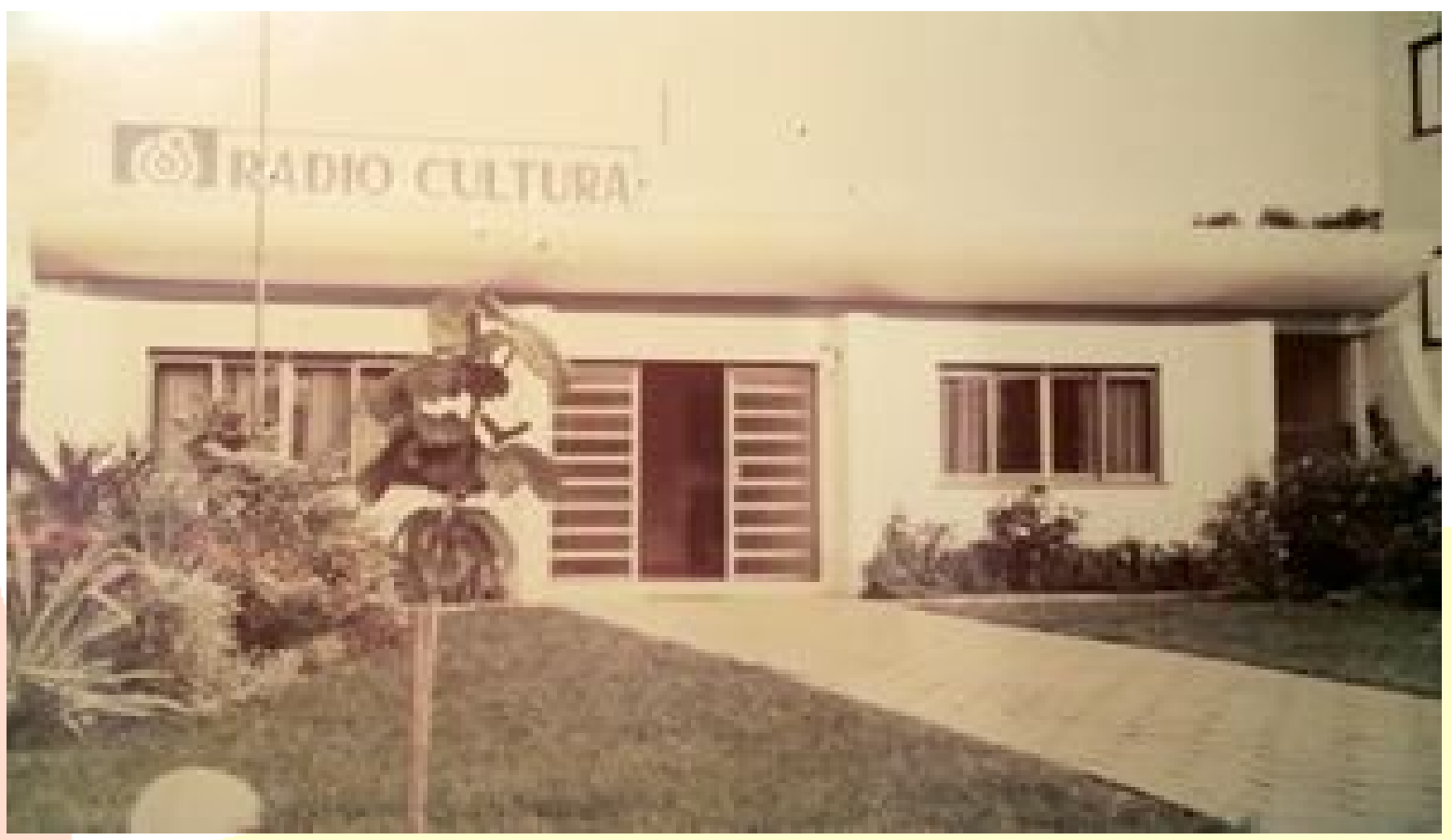

Fonte: Fanpage da Rádio Cultura. www.facebook.com/RadioCulturaSaoBorja

A Rádio Cultura AM tem seu surgimento após o fim da primeira emissora de rádio da cidade, em 1975. No ano seguinte, o Ministério das Comunicações abriu licitação de concorrência para a instalação de uma emissora de radiodifusão de amplitude modulada (AM) na "Terra dos presidentes". A concorrência foi vencida pelo grupo que formou a Empresa São-borjense de Comunicações Ltda, formada por nove sócios: os agricultores Ulrich Arns, Alfredo Arno Andres; o pecuarista Bernardino Lopes Ferreira; o agricultor e comerciante Francisco Carlos Banderó; o contabilista Carlos Ney Azambuja Brites; os comerciantes Silvino Nicolli, Sary Azambuja Amilíbia, comerciante; o advogado Arneldo Matter; e o administrador de empresas Roque Auri Andres. Assim a primeira transmissão ocorreu no ano de 1977, conforme mostra a Foto 2. 
Foto 2: Inauguração do transmissor da Rádio Cultura, em 1977.

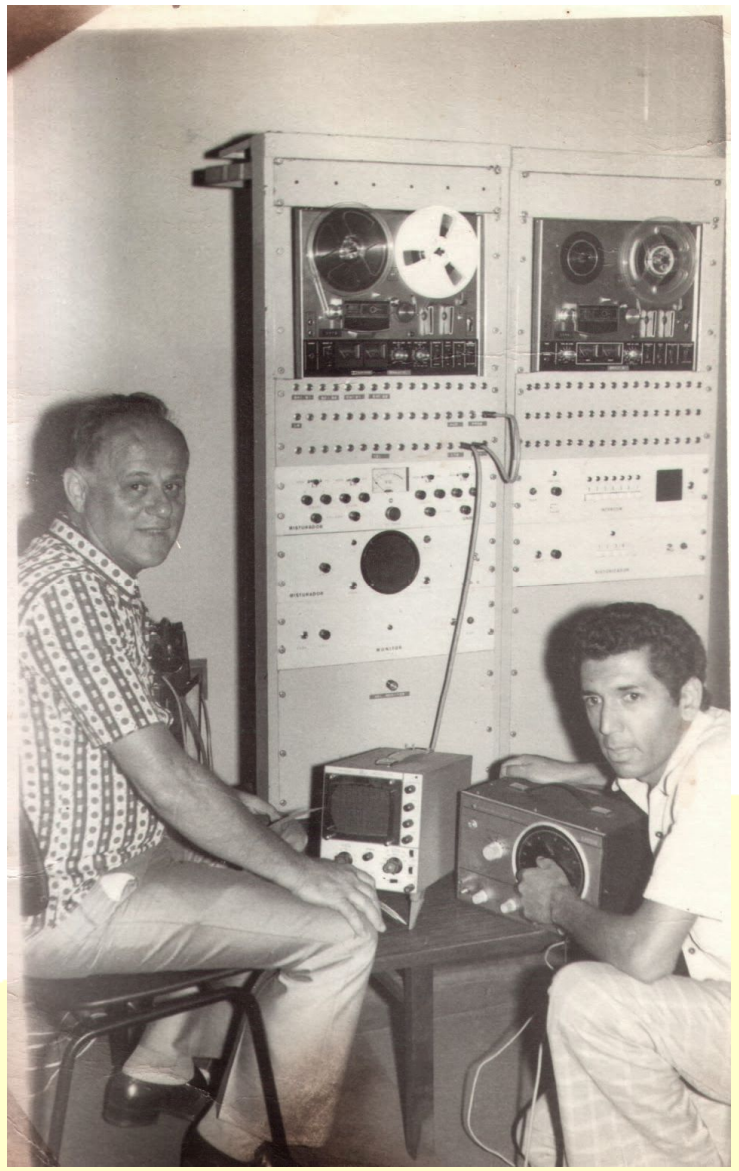

Fonte: Blog do Cezar Brites. http://cezarbrites.blogspot.com.br/2014/02/o-radio-em-sao-borja-partei-radio $16 . h$ tml

Inaugurada em pleno regime ditatorial, a Rádio Cultura AM é um bom exemplo para a abordagem da rádio naquele momento político vivenciado pelo Brasil. A programação da emissora era constituída de músicas e notícias rápidas e com inserções publicitárias. Para obtermos as informações necessárias para esta pesquisa, visto que há carência de registros formais sobre aquele momento histórico, realizamos entrevista com o José Antônio Degrazia, um dos funcionários da emissora com vários anos de serviços prestados e que vivenciou todo aquele momento histórico, sendo radialista desde 1959. Por ter uma ligação com o presidente João Goulart, a cidade de São Borja era alvo intenso de fiscalização dos militares, o que incidia também numa maior censura da emissora local:

Foi um período extremamente difícil pra todos nós, porque existia uma censura, sim! Músicas, noticiários, tudo obedecia ao sistema de censura, nada poderia ser divulgado na rádio sem passar pelo efeito de censura. Isso já dificultava, sobremaneira, por exemplo, o trabalho do comentarista. Não se podia comentar o fato. Qualquer fato não poderia ser divulgado antes de passar pela censura. Então, neste período aí foi que floresceu o futebol, o esporte. Ainda mais, né? 
Porque sempre o esporte teve a preferência do brasileiro, de uma forma geral. Mas no esporte a gente podia falar! Não se falava em política, falava em futebol. (Entrevista com José Antônio Degrazia, 2015).

Devido à censura que a emissora sofria, o radialista lembra ainda como era a dificuldade dos profissionais para fazer a programação musical que era veiculada. Ele recorda que todo conteúdo musical, assim como já era feito com o noticiário, deveria passar pela aprovação dos censores locais.

\begin{abstract}
A Cibele, professora de piano, uma extraordinária conhecedora de música. Ela tinha dificuldade em fazer a programação da rádio. Porque certas músicas foram censuradas, então não podia tocar. Tinha que enviar a programação, como o noticiário, pra censura, era tudo censurado. Discos novos que chegavam eram submetidos à censura. Assim era o período. (Entrevista com José Antônio Degrazia, 2015).
\end{abstract}

Segundo a opinião do entrevistado, a rádio presenciou um momento de limitação da liberdade de expressão, o que podia ser verificado no conteúdo que podiam transmitir para a audiência. Devido a essas limitações na linha editorial que não eram de conhecimento de toda a população, a emissora foi considerada pela população local como ligada aos grupos políticos que dominavam o cenário naquele momento. De acordo com o José Antônio Degrazia, a rádio sempre buscou estar isenta em prol da preservação da isonomia do veículo de comunicação. Em especial sobre o período ditatorial militar, o radialista comentou que devido à impossibilidade de fazer comentários mais profundos sobre a política local e nacional, uma solução para manter um conteúdo de qualidade para o público foi o investimento das coberturas futebolísticas.

\begin{abstract}
A orientação dentro da emissora era, dentro do limite permitido pela Ditadura, de um trabalho isento. Agora, claro que, chega lá ele determina a Ditadura, determina que isso tem que ser publicado, aquilo tem que ser feito, a rádio não pode fugir. Como nenhum cidadão brasileiro poderia fugir daquilo ali sob pena de sofrer os efeitos e as punições da época. Então era difícil! E a rádio viveu muito tempo sob esse estigma de ser uma rádio governista. (Entrevista com José Antônio Degrazia, 2015).
\end{abstract}

Além do enfoque no futebol, a rádio também promovia a cobertura do carnaval da cidade (Foto 3) por também ser um tipo de conteúdo que não sofria atenção dos censores, uma vez que não atingia a política de "segurança nacional". 
Foto 3: Primeira equipe de transmissão de carnaval da Rádio Cultura AM em 1978.

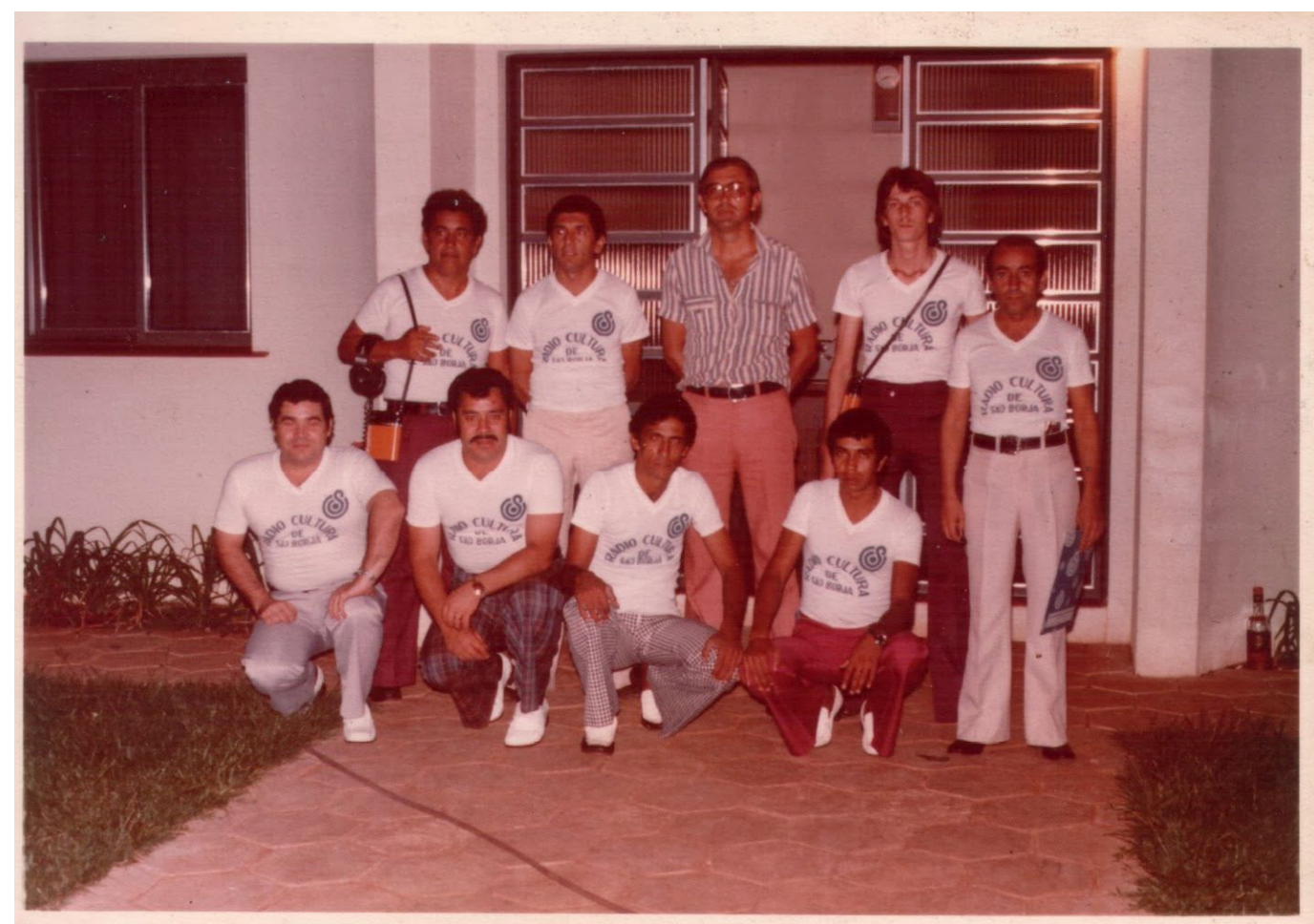

Fonte: Blog Cezar Brites. http://cezarbrites.blogspot.com.br/2014/02/o-radio-em-sao-borja-parte-iradio $16 . \mathrm{html}$

Todas essas limitações que a censura impunha à Rádio Cultura AM pode ser explicada também pelo fato dela ter sido a substituta da primeira emissora da cidade que fora fechada pelo governo militar. Assim, a Rádio Fronteira do Sul começou a receber as primeiras fiscalizações dos miliares em 1967 para a averiguação de irregularidades. Na época, o presidente da emissora ainda fez várias tentativas para contornar as proibições dos censores, mas não conseguiu evitar o fim da rádio. Para José Antônio Degrazia, no caso da rádio Cultura $\mathrm{AM}$, mesmo que vários dos seus sócios tivessem alguma ligação com o governo da época, eles não conseguiam contornar as limitações impostas pela censura. Entretanto a ligação dos seus donos com o governo militar levou a audiência são-borjense a vincular a emissora com o regime ditatorial, algo que ficou na memória da população da época.

A rádio Cultura ela sofreu. Ela passou por um período muito difícil no começo. Porque ela veio substituir a emissora antiga que existia aqui e que foi fechada em função da política, por problemas políticos. O que é um outro problema. Aí a rádio Cultura, quando ela abriu, a maioria dos membros da direção da emissora pertencia ao partido do governo, vamos dizer, ou eram simpatizantes dentro dessa área. Então criou-se aquela sensação de que era uma emissora governista, da ditadura, filha da ditadura. (Entrevista com José Antônio Degrazia, 2015). 
No relato de José Antônio Degrazia, a Rádio Fronteira do Sul teve suas transmissões interrompidas em 1975. Na cidade de São Borja, algumas pessoas acreditam que o fechamento dessa emissora deve-se ao medo de que ela servisse em algum momento para fins políticos dos partidários do presidente exilado João Goulart. As pessoas acreditam que Jango teria doado a rádio para os funcionários alguns anos antes do Golpe de 1964 através de uma carta, porém os novos donos não atualizaram a documentação oficializando a doação. Assim, para o governo militar, a emissora de rádio ainda pertencia ao ex-presidente cassado pelo regime.

Após o fechamento da Rádio Fronteira do Sul, São Borja ficou dois anos sem emissora local, o que gerou muitos malefícios para a população, visto que por ser região de fronteira, há dificuldade para se efetivar a comunicação e obter informações sobre o que acontecia no Rio Grande do Sul, no Brasil e no mundo. Apenas em 1977, a cidade passou a ter esse tipo de informação, evidentemente dentro dos limites da censura do regime militar, com a implantação da Rádio Cultura AM.

\section{Considerações Finais}

Neste estudo, intentamos abordar a questão da memória radiofônica a partir do contexto são-borjense, tendo pano de fundo o momento histórico da Ditadura Militar, ao qual o Brasil foi submetido por mais de duas décadas. Assim, a partir da cidade de São Borja-RS, por ser a Cidade Natal do presidente João Goulart, cujo mandato foi cassado pelos militares, tivemos um exímio ambiente para estudar essa relação entre mídia, história e política.

Através da experiência da Rádio Cultura AM, podemos verificar como a questão da Ditadura Militar e, consequentemente, da repressão e da censura ficaram sedimentadas na memória coletiva, sendo que nossa abordagem foi construída a partir da experiência de um radialista que vivenciou todo aquele momento.

Cabe ressaltar ainda a grande importância do rádio para a cidade situada na fronteira do Brasil com a Argentina, distante dos grandes centros, e na época o principal e mais contemporâneo meio de comunicação. Com a Rádio Fronteira Sul e depois com a Rádio Cultura AM, pudemos observar o quão à cidade sofreu com os impactos da midiatização emergente: inicialmente durante o governo do são-borjense Getúlio Vargas até as represálias do Governo Militar. Através da inserção da Empresa de Comunicação 
São-borjense (Rádio Cultura AM), o cenário foi aos poucos se modificando para receber as novas informações sobre a região, ainda que com todas as limitações impostas pela censura.

Observamos ainda que mesmo com a vigília ditatorial, a censura não foi o suficiente para inibir por completo a programação da rádio. Como ressaltou o radialista José Antônio Degrazia, o período militar os obrigou a investir em novas abordagens de trabalho na emissora de modo a preservar a audiência e não atrair a censura: a solução foi a cobertura futebolística. Com o esporte, os comentaristas se destacavam pela possibilidade em "falar o que pensavam" sobre os jogos que narravam, sem vínculos com a ideologia política dominante e, portanto, sem necessariamente temer por suas represálias.

Por fim, diante dessa experiência radiofônica são-borjense, consideramos que a mídia é um fator central da vida política. Já naquele período, os militares sabiam que deviam controlar os meios de comunicação, ao mesmo tempo em que utilizavam as rádios para dar visibilidade ao governo.

\section{Referências Bibliográficas}

ALBERTI, V. Tratamento das entrevistas de história oral no CPDOC. Rio de Janeiro: CPDOC, 2005.

COLVERO, Ronaldo; MARTINEZ, Iris Nabolotnyj; MIRANDA, Caroline Rodrigues. São Borja espaço de possibilidade: das missões à atualidade. In: ALMEIDA, Cristóvão Domingos; ABREU, Carmen. Comunicação Integrada: contribuições na conquista da cidadania. Rio Grande do Sul: Erechim, 2014.

CRUIKSHANK, Julie. Tradição oral e história oral: revendo algumas questões. In: AMADO, Janaína; FERREIRA, Marieta de Moraes. Usos e Abusos da história oral. Rio, Editora FGV, 2000.

FERNANDES, F. A ditadura em questão. São Paulo: T. A. Queiroz, 1981.

FLICK, Uwe. Uma introdução à pesquisa qualitativa. Porto Alegre: Bookman, 2004.

GASPARI, Elio. A ditadura derrotada. São Paulo: Companhia das Letras, 2003. 
. A ditadura encurralada. São Paulo: Companhia das Letras, 2004.

. A ditadura envergonhada. São Paulo : Companhia das Letras, 2002a.

. A ditadura escancarada. São Paulo: Companhia das Letras, 2002b.

HALBWACHS, Maurice. A memória coletiva. São Paulo: Vertice, 1990.

HARRES, M. M. História oral: algumas questões básicas. Anos 90, Porto Alegre, v. 15, n. 28, p. 99-112, dez. 2008.

HAUSSEN, Doris Fagundes. Rádio e política: tempos de Vargas e Perón. Porto Alegre: EDIPUCRS, 2001.

MACHADO, Juremir da Silva. Vozes da Legalidade: política e imaginário na era do rádio. Porto Alegre: Sulina, 2011.

MOREIRA, Sonia Virgínia. O rádio no Brasil. Rio de Janeiro: Rio Fundo Ed., 1991.

PRADO, Magaly. História do rádio no Brasil. Rio de Janeiro: Livros de Safra, 2012.

THOMPSON, John. B. Ideologia e cultura de moderna: teoria social crítica na era dos meios de comunicação de massa. Petrópolis (RJ): Editora Vozes, 1995. 